\title{
THE EFFECT OF ASSYMETRICALLY DOMINATED ALTERNATIVES FOR CHOSEN PRODUCT CATEGORIES
}

\author{
[Efekt asymetricky dominované alternativy u vybraných kategorií produktů]
}

\author{
Radka Kubalová ${ }^{1}$, Martin Klepek ${ }^{2}$ \\ ${ }^{1}$ Slezská univerzita, Obchodně podnikatelská fakulta, Univerzitní nám. 1934/3,733 40 Karviná \\ Email:kubalova@opf.slu.cz \\ ${ }^{2}$ Slezská univerzita, Obchodně podnikatelská fakulta, Univerzitní nám. 1934/3,733 40 Karviná \\ Email:klepek@opf.slu.cz
}

\begin{abstract}
When faced with the choice problem involving two products each superior in a different dimension, an addition of an asymmetrically dominated alternative into the choice set might shift the consumer's preferences towards the dominant alternative. In this article, the effect of asymmetrically dominated alternatives is explored on a sample of Czech consumers involving four different product categories - lunch meals, vacation destinations, gym season tickets, and washing machines. The research question is whether there might be any significant differences in the strength of the effect on choices of Czech consumers. The analyzed data were obtained in an experiment with 260 participants and the effect sizes are tested by the Chi-squared test. The presence of the decoy effect is confirmed only for two product categories, washing machines, and gym season tickets. For the remaining two product categories the effect was not confirmed. This study and its findings test the theory of consumer decision making about the decoy effects in the case of specific products and implications for business considering using the decoy effect are made.
\end{abstract}

Keywords: consumer behaviour, consumer decision-making, decoy effect, marketing.

JEL classification: D91, M31

Received: 29.6.2020; Reviewed: 24.7.2020; 29.8.2020; Accepted: 9.9.2020

\section{Introduction}

For modern businesses, it might be extremely valuable yet extremely difficult to find out what exactly leads their customers to buy or to not buy the offered products. According to the classical decision making models, consumers' decisions are context-independent. Therefore, their choices should not be influenced by the presence of such alternatives which are clearly less desirable versions of the other options.

However, the researches made in the last decades, especially in the behavioral economics and decision-making field, demonstrate that everyday decision making of economic agents is not fully based on rationality because human perception and judgement unconsciously succumb to an influence of so-called biases and heuristics. For example, the influence of context which might influence the consumer's choice and preferences has been reported. The effect of asymmetrically dominated alternatives is one of such context effects that goes against the theory of rational choice and attracts the attention of both scientists and marketing managers. According to some authors like Bačová (2013, p. 62), it is one of the most known and most discussed context effects, both in scientific fields and laic public.

The article aimed to find out if it is possible to change the probability of consumers choosing a particular product over another one by introducing into the choice set an asymmetrically dominated alternative. In this article, the authors present the results of the findings of the asymmetrically dominated alternative effect on the Czech consumers for four product categories, different in their characteristics. One tangible product (washing machines), one 
semi-tangible product (lunch menu), and two pure services (holiday trip and gym season tickets) were chosen.

The first chapter is dedicated to the phenomenon of asymmetrically dominated alternatives. The second chapter describes the methods used in our research and the final chapter summarizes the results and findings obtained from the research and discusses its limitations.

\section{Literature review}

Entering the market with a new product or brand might raise an important question for the marketers about how this action changes the market shares of the original products or brands. This problem can be easily brought into a decision making of an individual when he is presented with an offer that has been broadened by a new product. In the past, it was generally assumed that that the appearance of a new alternative lowers the market share of the other alternatives proportionally, meaning the market share of all alternatives decreases but the original ratios between the alternatives stay the same. According to this choice axiom, the probability of choosing one alternative over another one is not influenced by the presence or absence of any other alternatives in the choice set (Luce 1977, p. 215-216).

This possibility had been introduced by Huber et al. (1982) who managed successfully to raise the popularity of a target alternative over the competitor alternative by simply adding a third, slightly worse, alternative into the original choice set. Being the first ones to introduce the socalled asymmetric dominance effect for 6 different, mostly tangible, products, they demonstrated this effect by offering the experiment participants two different products of the same category (e.g. beer). In a choice set of two alternatives $\mathrm{T}$ (target) and $\mathrm{C}$ (competitor), the popularity of $\mathrm{T}$ might be raised by adding an alternative $\mathrm{D}$ which is similar to alternative $\mathrm{T}$ but slightly inferior in one or more characteristics.

This newly added option is called asymmetrically dominated alternative because one of the original alternatives is clearly superior to it in its characteristics and therefore dominates the option. Some authors found out that the decoy was effective even when it was listed as currently unavailable or sold-out in the offer. These kinds of decoys that are present but not available to be chosen by the decision-makers are called phantom decoy and seem to be practically used in many areas. For example, Park and Jang (2018) confirmed that presenting information about sold out tourist destination raises the purchase intention for target destinations similar to the sold-out ones.

Other authors focused their research on testing the use of asymmetrically dominated alternatives for different specific products. Ariely (2008, p. 7-9) confirmed this assumption in an experiment connected to the real offer of The Economist subscription which was presented on the newspaper's website. Just like the potential customers the participants of the experiment were choosing between tree versions of the subscription. Gonzalez-Prieto et al. (2013) tested the effect in the purchase process of the airplane tickets. Duriník (2013) examined the use of asymmetrically dominated alternatives in a purchase situation where a consumer chooses between different warranty policies for the same product and found out that adding an inferior alternative is a successful strategy to raise the popularity of paid prolonged warranty policy instead of regular warranty policy which is guaranteed by the state. Many authors did not focus thein research of asymmetric dominance effect for the restaurant meals to confirm the assumption but Shoemaker (1994) who explored the effect on the perception of the restaurant menu prices and also recommends to add a decoy alternative to increase the 
profitability of the product line because such alternative will create a reference frame for evaluating the rest of the options.

Three conducted meta-analyses suggest that decoys can increase the likelihood of choosing the dominating alternative by 12 to $18 \%$ (Heath and Chatterjee 1995; Milberg et al. 2014; Yang and Lynn 2014). The empirical testing in the real market by Wu and Cosguner (2020) implies a 14,3\% rise in gross profits for the retailer due to the decoy effect which supports the possible practical implications for the managers. According to Rooderkerk et al. (2011), the companies can use the effect to create strategies that would generate them more profit by raising the share of more profitable products and lower the demand for less profitable products.

However, there are recently emerging also studies pointing out the influence and the effect itself to be overestimated and there is a number of conditions and limits moderating the effect and challenging its practical implications (Frederick et al. 2014). The attention has been given to the situational variables or so-called experiment design moderators such as the products' country of origin (Chuang and Yen 2007), the presentation format of the attributes and alternatives, stylization of the choice task or ability to directly experience product attributes (Frederick et al. 2014; Ha et al. 2009; Yang and Lynn 2014) or choice and time constraints (Dhar and Simonson 2003; Lin et al. 2008). There were reported also person-based or individual-specific variables as motivational influences (Levav et al. 2010) or thinking styles (Mao and Oppewall 2012). So far, it is not assumed that the context effect would be moderated by any cultural or national factors.

In this article, authors decided to explore if the presence of such asymmetrically dominated alternatives will create the same effect on the Czech consumers and might be therefore used to influence their purchase decision in the case of four specific product categories.

\section{Methods and data}

For the research on testing the effect of decoys for our chosen products, it was necessary to collect relevant primary data. In this case, an experiment similar to those carried out in previous studies (e.g. Gonzales-Prieto et al. (2013) or Ariely (2008)) appeared to be the most suitable technique of collecting such data. It is assumed that the participants can compare and evaluate the presented options according to their subjective assessment and choose the one fitting their preferences the best even without the need for a real purchase taking place afterwards. Therefore, in this sense, it is assumed the experiment is still sufficiently meaningful.

\subsection{Experiment design}

To answer the research question whether the presence of a decoy influences the consumers' choices for chosen product categories, the null and alternative hypothesis for statistical testing were formulated as follows:

H0: The presence of the decoy does not lead to a statistically significant rise in the popularity of the target alternative.

H1: The presence of the decoy does lead to a statistically significant rise in the popularity of the target alternative.

To test the hypothesis, it was necessary to create two versions of the offers containing the chosen product alternatives. As showed in the Table 1 which is summarising the experimental 
design, the product categories that were chosen for testing were lunch meals, vacation destinations, gym season tickets, and washing machines.

Table 1: Overview of experimental design

\begin{tabular}{|l|l|l|l|l|}
\hline Product category & Choice set & Target & Competitor & Decoy \\
\hline $\begin{array}{l}\text { Lunch meals } \\
\text { Vacation destinations } \\
\begin{array}{l}\text { Season tickets } \\
\text { Washing machines }\end{array}\end{array}$ & Control & $\mathrm{x}$ & $\mathrm{x}$ & - \\
\cline { 2 - 5 } & Experimental & $\mathrm{x}$ & $\mathrm{x}$ & $\mathrm{x}$ \\
\hline
\end{tabular}

Source: own

These offers represent the decision-making problems for the participants and while one version for the control group contains only two different alternatives (target and competitor) the other version for the experimental group contains also the decoys which are asymmetrically dominated by the target alternative. Authors test a hypothesis that the presence of the decoy leads to the rise of the probability of consumers choosing the original target alternative.

In the following tables, there are listed the constructed offers (with the decoys involved), and the assigned competitor-target-decoy function of each alternative is added in the brackets. The assigned function of the alternatives was of course not available to the participants of the experiment.

Table 2: Offer no. 1 - lunch meals

\begin{tabular}{|l|}
\hline Which of the following meals would you choose and order in the restaurant? \\
\hline$\bullet 120 \mathrm{~g}$ Chicken fried steak with potato puree and carrot salad ........ 89 CZK (competitor) \\
\hline$\bullet 150 \mathrm{~g}$ Serbian pork risotto with root vegetables, peppers, and grated cheese on top, pickles, and onion ......... \\
109 CZK (target) \\
$\bullet 150 \mathrm{~g}$ Turkey breast marinated in sea salt and fresh sage leaves, grilled in a slice of bacon and served with a \\
small vegetable salad and potatoes ........ 159 CZK (decoy) \\
\hline
\end{tabular}

Source: own

The first offer, as shown in the Table 2, contained lunch meals of a restaurant menu and was inspired by the suggestion of Shoemaker (1994) and Ariely (2008) to add more expensive meal into the choice set which may lead to the shift of the reference frame and rise of the demand for the second most expensive meals. The offer no. 1 is supposed to test this assumption on Czech consumers. The meals were chosen randomly and were priced according to the real Czech restaurants' menu which could be found online around the time of the research.

Table 3: Offer no. 2 - vacation destinations

\begin{tabular}{|l|}
\hline Which of these holiday destinations would you choose for your trip? \\
$\bullet 4$ days in a $3 *$ hotel in Rome with breakfast ........ 4500 CZK (competitor) \\
\hline$\bullet 4$ days in a $3 *$ hotel in London without breakfast .......5 400 CZK (decoy) \\
\hline$\bullet 4$ days in a $3 *$ hotel in London with breakfast ........5 400 CZK (target) \\
\hline
\end{tabular}

Source: own

As Table 3 shows the second offer was involving two European destinations - London and Rome. The second offer was constructed to test whether adding an option of a trip to London without breakfast will shift the preference of the consumers towards the London with the breakfast option at the expense of the cheaper Rome alternative. London with breakfast and without were both priced the same although it might seem illogical at first glance. However, London without breakfast is supposed to be the decoy which authors do not suppose someone 
would really choose, and if it is chosen after all. It is assumed it will generate higher profits for the seller (considering the option without breakfast is also less costly for the seller/service provider). The main aim of the decoy is to raise the attractiveness of the other London option which is more expensive than Rome and it can be expected the seller would prefer to sell out the more expensive option first.

Table 4: Offer no. 3 - gym season tickets

\begin{tabular}{|l|}
\hline Which of the following types of gym's season tickets would you most likely choose to buy? \\
\hline$\cdot 10$ entries (valid for 3 months) $\ldots \ldots \ldots . .850$ CZK (competitor) \\
\hline$\cdot 20$ entries (valid for 6 months) ...... 1800 CZK (decoy) \\
\hline$\cdot 20$ entries (valid for 6 months) with entries to sauna ........1 800 CZK (target) \\
\hline
\end{tabular}

Source: own

The third offer, shown in Table 4, was connected to the services, namely season tickets for a gym. Competitor alternative represents 10 entries for a price of $850 \mathrm{CZK}$ and the target alternative stands for 20 entries with sauna for $1800 \mathrm{CZK}$. It is assumed it might be difficult for the participants to decide whether the entries with sauna have a value of $1800 \mathrm{CZK}$ in total. Participants can most likely tell 20 entries should have a value of $1600 \mathrm{CZK}(2 * 850$ CZK) but it might be problematic for them to decide whether using the sauna has the value of remaining $200 \mathrm{CZK}$. Therefore, the decoy option was introduced to the set to observe whether its addition causes the rise in the demand for the entries with the sauna at the expense of the competitor.

Table 5 shows the last choice set involving a tangible product - washing machines. Whirpool was randomly chosen as the brand for all of the presented products to prevent the participants from choosing according to the brand perception if the brands differ among the alternatives. Therefore, the possible brand effect was omitted from this particular research. The washing machines were compared by three key dimensions - price, capacity, and revolutions.

Table 5: Offer no. 4 - washing machines

\begin{tabular}{|l|}
\hline Which of the following washing machines would you most likely choose to buy? \\
\hline$\bullet$ Whirlpool XX with capacity $5 \mathrm{~kg}$ and 1000 revolutions per minute $\ldots \ldots \ldots .7000 \mathrm{CZK}$ (competitor) \\
\hline$\bullet$ Whirlpool YY with capacity $5,5 \mathrm{~kg}$ and 1200 revolutions per minute $\ldots \ldots \ldots .8000 \mathrm{CZK}$ (decoy) \\
\hline •Whirlpool YY with capacity $5,5 \mathrm{~kg}$ and 1200 revolutions per minute $\ldots \ldots \ldots .8000 \mathrm{CZK}$ (decoy) \\
Source: own
\end{tabular}

There was an effort to price the products in each presented offer in a way the prices would match as much as possible the real market prices (eg. according to the similar products and services available on the internet). In most of the cases (except offer no. 1), the final prices were round up to hundreds or thousands CZK and the decoy prices were adjusted to fulfill the role of the decoy.

The shown offers were put into a survey in two versions. Version A containing the decoys was used in the case of the experimental group and decoy-less version B was presented to the control group since it was also necessary to know how participants make decisions when decoys are absent if the goal was to find out how their presence influences the choices. This kind of decision problem design allows authors to test the hypothesis that the presence of the decoys raises the probability of consumers choosing the target product at the expense of the competitor. 


\subsection{Data collection and sample}

Once the decision problems were created and the survey was formed it was necessary to decide how potential participants of the experiment will be chosen and how the survey will be presented to them. The most economical and generally the most convenient appeared to be an electronic form. Two versions of the constructed survey were presented to the participants via Google Forms which is a free tool for creating a personalized survey, their sharing, collecting answers, and easy transfer of data to a spreadsheet.

Having two versions of the survey and two groups of participants, it was also necessary to choose a certain criterion for dividing the participants into the control and experimental group so there no intentional and unintentional manipulation would be occurring when placing the participants into the groups. For that reason, it was decided beforehand that participants will be divided according to the first letter of their surname. To get the most precise alphabetical separation of the groups, a frequency of surnames in the population according to the Czech Statistical Office, and then it was calculated the alphabetical separation should be as follows:

- A-L - experimental group (survey with the decoys)

- M-Ž - control group (survey without the decoys)

The assumption is that alphabetical placement of surnames does not influence on the respondent's reaction to the presence of the decoys or important characteristics of the respondents, meaning it is assumed there is no significantly larger number of older people or women in one group over the other one. Therefore, using this way of placing the respondents into the groups appears to be sufficient and objective.

The last question to answer before collecting the data was connected to the structure of the tested sample. The experiment was made for Czech men and women over 18 years old, regardless of their income category. The most popular social media Facebook.com was used to address and communicate with the potential respondents who were found in the public groups or fan pages of large Czech cities - eg. fans of Prague (580 thousands of fans in total), Brno (69 thousands of fans in total), Liberec (17 thousands of fans in total), or members of the public group Milujeme Olomouc (18 thousands of fans in total). The respondents who agreed to participate were then given the link to the appropriate version of the survey.

Data was collected in this manner from 5. 3. 2018 to 21. 3. 2018 and 770 potential respondents were addressed in total. 260 participants reacted positively and took part in the experiment -128 in the control group a 132 in the experimental group. The final sample structure by gender is following: $46 \%$ females and $54 \%$ males in the experimental group, 54 $\%$ females and $46 \%$ males in the control group. Based on the age groups, the structure of the sample for the experimental group is following: 18-27 (44\%), 28-37 (19 \%), 38-47 (21\%), $48-57(10 \%), 58+(6 \%)$. For the control group, the age structure is following: 18-27 (24 \%), $28-37(23 \%), 38-47(24 \%), 48-57(23 \%), 58+(6 \%)$.

\section{Results and discussion}

In this chapter we present and discuss the results and findings based on the obtained data. The end of the chapter is dedicated also to the limitations of this research.

\subsection{Experiment results}

The first offer respondents reacted to contained lunch menu showing three meals among which the respondents were to choose the one they would most likely order at the restaurant. 
Table 6 shows in detail how the participants were deciding between the alternatives in this case.

Table 6: Popularity of the alternatives for offer no. 1 - lunch menu

\begin{tabular}{|l|c|c|c|}
\hline & Competitor & Target & Decoy \\
\hline Decoy absent & $73 \%$ & $27 \%$ & - \\
\hline Decoy present & $52 \%$ & $11 \%$ & $37 \%$ \\
\hline
\end{tabular}

Source: own

When the decoy was absent it can be observed the competitor was highly popular with $73 \%$ of participants choosing it. However, adding the decoy in the case of the lunch menu led to a decrease of popularity for both the competitor and the target and it is given by the fact that 37 $\%$ of respondents found the decoy itself more attractive. Some authors like Heath and Chatterjee (1995) or Duriník (2013) in their analysis usually consider the decoy synonymous with the target alternative. Authors believe that can be done in the cases when the decoy is a similar version of the target with lower characteristics and therefore it might not be important for the seller if the consumer chooses the target or the asymmetrically dominated version of the target that comes with the same or higher price. The authors lean towards this opinion and will do so for the rest of the product categories. However, authors do not do so for the offer no. 1 as it is not considered the condition of the similarity is fulfilled in this particular case as there are surely more differences than only higher price between the pork risotto (target) and grilled turkey breast (decoy).

Therefore, even without the need for further analysis, the decoy in the form of a more expensive meal, in this case, did not bring the desired effect of raising the attractiveness of the second most expensive. Although it is not possible to confirm the exact causes of why the decoy failed several factors or their combination can be determined:

1. The low price of the decoy - it is possible that the price set for the decoy (although nearly $50 \%$ higher than the target's price) still was not high enough for the consumers to seem unaffordable and led to the decision to get at least the second most expensive meal.

2. Specific product and decision-making - it is true that choosing a lunch or other meals is an everyday problem for every individual and therefore the decision making might not request a high level of interest as a decision about other, more expensive products that customers buy less often. Moreover, consumers might have a strong stable preference for this product and are following their taste and their dining habits rather than factors like weight or price of the meal. If an individual does not eat pork meat at all or strongly prefers poultry then it is possible no decoy in the choice set might make them shift his preference.

3. Great differences between each alternative - in this offer, there were significant differences between the alternatives and it is possible that the routine decision making based on strong preferences from the previous part could be prevented by using a more similar variety of the same meal, for example, limit the whole offer to 3 versions of beef steaks or 3 different types of sea fish. Lessening the differences might lead to increasing the complexity of the decisionmaking and the decoy that diverts attention towards the target option could be used more effectively.

4. Moreover, this result could be partly explained also by previous findings of the effect as made by Frederick et al. (2014, p. 4) or Yang and Lynn (2014) who found out that verbal description opposed to a numeral description of the alternatives moderates the effect. While 
this offer included both verbal (specific meal description) and numeral description (quantity of meal and price), the hybrid format presentation was less stylized and the participants might have not base their choices on the comparison of the numeral attributes but rather the verbal description of the products.

Without further analysis, in this case, the assumption that the presence of the decoy leads to raising the attractiveness of the target for the lunch menu product category is rejected.

Next, there is presented the table 7 where are shown the participants' choices for the offer no. 2, that was focusing on holiday trips to two European cities - London and Rome.

Table 7: Popularity of the alternatives for offer no. 2 - a holiday destination

\begin{tabular}{|l|c|c|c|}
\hline & Competitor & Target & Decoy \\
\hline Decoy absent & $66 \%$ & $34 \%$ & - \\
\hline Decoy present & $61 \%$ & $31 \%$ & $8 \%$ \\
\hline
\end{tabular}

Source: own

Comparing the results when the decoy was absent and present shows that the competitor more popular than the target no matter whether the decoy was involved or not. It is quite surprising that the addition of the decoy did not lead to any significant change in the choices, the number of people choosing competitor decreased by $5 \%$ and the number of people choosing the target dropped by $3 \%$

Similar to the previous offer, the popularity of the competitor and the target dropped in favour of the decoy itself which was chosen by $8 \%$ of participants. However, in this case, the decoy can be considered synonymous to the target due to the reason decoy is basically the same as the target, only worse in one dimension and that is the breakfast included in the price. When the decoy popularity is added to the target popularity it means the popularity of the preferred target alternative reaches up to $39 \%$, therefore rising by $5 \%$ compared to when the decoy was absent.

To be able to evaluate whether the authors ' hypothesis of decoy presence causing a rise in the attractiveness of the target alternative can be accepted, Pearson's chi-squared test was carried out and its result is to accept the null hypothesis H0. The result shows that at a 5\% significance level it is possible to consider the choices to be independent on the decoy presence and they are to be the result of an independent (random) distribution $(\mathrm{T}=0,702856$; critical value $\mathrm{K}=3,841459 ; \mathrm{T}<\mathrm{K})$. Due to this reason, the hypothesis of decoy presence causing a rise in the attractiveness of the target alternative for the holiday destination product category needs to be rejected.

Although even in this case it is not possible to confirm why the decoy did not bring the derired effect on the consumers' decision-making one of the possible explanations is that the destination itself was not that important factor for Czech consumers (in case they did not naturally have any significant preferences towards one of the options) as opposed to the price. As explored by Tomek et al. (2013), the top three prevailing segments based on an attitude of Czech consumers towards money is ,Rational' with $27,3 \%$, ,Timid' with $23,5 \%$ and ,Scrooge‘ with $22,3 \%$ which notes quite high sensitivity towards money and prices held by Czech consumers as opposed to a ,Spender' attitude.

As can be noticed the difference between London and Rome with breakfast was the destination and the price. The price difference was as high as $900 \mathrm{CZK}$ and this could be too 
much especially if the respondents did not care about the destination itself. In this case, the participants could have compared London and Rome and come to the conclusion Rome is a better deal overall as the very same services were included (same length of the trip, same $3^{*}$ hotel, breakfast included) and it was even 900 CZK cheaper than the London which could be the main factor in this case as well. However, this remains the authors' own assumption.

The next offer which was presented to the participants of the experiment was focused on the gym season tickets and in the Table 8 it can be observed how the respondents were choosing between the alternatives once again.

Table 8: Popularity of the alternatives for offer no. 3 -gym season tickets

\begin{tabular}{|l|c|c|c|}
\hline & Competitor & Target & Decoy \\
\hline Decoy absent & $59 \%$ & $41 \%$ & - \\
\hline Decoy present & $30 \%$ & $67 \%$ & $3 \%$ \\
\hline
\end{tabular}

Source: own

This time the results show that when the decoy was absent the majority of the respondents have chosen the competitor unlike when the decoy has been added. In that case, the target appeared to be more popular which corresponds with the typical demonstration of the functioning decoy.

The ratio between the alternatives when the decoy was absent was following - $59 \%$ for the competitor and $41 \%$ for the target. Meanwhile, when the decoy was present $67 \%$ has chosen the target, $30 \%$ has chosen the competitor and $3 \%$ has chosen the decoy itself. This time once again the decoy can be considered synonymous to the target due to the high degree of the similarity between the alternatives.

The obtained data were once again chi-squared tested at a 5\% significance level and the result is to reject the null hypothesis $\mathrm{H} 0$ of independence $(\mathrm{T}=22,22724733$; critical value $\mathrm{K}=3,841459149 ; \mathrm{T}>\mathrm{K}$ ), meaning there is $95 \%$ probability that the different choices of participants when the decoy was present and absent are not random and authors' chosen hypothesis that the presence of decoy causes a shift of preferences towards the target for season tickets product was supported.

Last, the effect of asymmetrically dominated alternatives was tested on the washing machines' product. Like in all the previous cases, even now the participants' choices for each alternative are shown in the following Table 8.

Table 9: Popularity of the alternatives for offer no. 4 - washing machines

\begin{tabular}{|l|c|c|c|}
\hline & Competitor & Target & Decoy \\
\hline Decoy absent & $45 \%$ & $55 \%$ & - \\
\hline Decoy present & $22 \%$ & $70 \%$ & $8 \%$ \\
\hline
\end{tabular}

Source: own

Table 9 shows that even when the decoy was absent respondents in the control group chose target more often, expressed as a percentage $45 \%$ of the respondents chose competitor and 55 $\%$ of them leaned towards the target alternative. Although the target was slightly more popular than the competitor even before adding the decoy it is still possible for the effect of the decoy to be observed if it raises the popularity of the target even more. 
This can be observed in this case as well. Once the decoy has been added the number of participants choosing competitors decreased by $23 \%$ and the popularity of the target grew further by $15 \%$. It was tested whether this change in the respondent's choices was statistically significant. According to the result of the chi-squared test at a 5\% significance level, the null hypothesis $\mathrm{H} 0$ of independence is rejected $(\mathrm{T}=15,90369008$; critical value $\mathrm{K}=3,841459149$; $\mathrm{T}>\mathrm{K})$ and the alternative hypothesis of influence of the decoy presence on the decision making in favour of target alternative for washing machines product category is therefore accepted.

\subsection{Reserach limitations}

The number of limitations can be detected in this type of research and some were already mentioned throughout the text. Firstly, the limitations lie in the sample size and structure. The authors of the paper are aware that the presented sample size is far from a sufficient representative sample of the Czech consumers and it would be necessary to verify the results with the help of additional extensive research. Despite this limitation, it is believed the data collected in this manner is still worth examining and provide useful insight into Czech consumers' decision-making behavior. The problem of the sample structure is partially given by the method of addressing the respondents via social media, specifically Facebook, and therefore, the sample structure in our research reflects the structure of Facebook users, e.g. majority of respondents being younger than 48 years.

Another limit preventing us from generalising the results is the fact the respondents were only facing hypothetical choices without the real purchase and therefore, the results might be a little bit different if the consumers face true economic consequences of their choices.

In the conducted experiment the participants were comparing two or three alternatives based on three key traits. While for some products used in the experiment (like gym season tickets, lunch meals) it might be a sufficient number of traits and alternatives to fully describe the product, for some products like washing machines providing only three traits meant a simplified version of the product description and some important features like energetic efficiency or aspect of brands were completely omitted in our research. However, if we consider the fact that consumers usually narrow the wide range of products available in today's market to the final two or three alternatives which meet their basic criteria then we can still find the situation of making a decision between few products based on the selected key traits they might differ in, just like in our research, applicable to the marketing reality.

\section{Conclusion}

The previous extensive research conducted by other authors in the area of individual decisionmaking research demonstrates that consumers are context-sensitive and their choices can be influenced by introducing an inferior option to the choice set. In this paper, the possibility of using these asymmetrically dominated alternatives or so-called decoys to influence the decision-making of the Czech consumers for 4 specific product categories was explored.

Analysing the collected data, it was found out that the presence of the decoy did not influence the consumers' decision-making in all four explored cases. In the product category lunch, it happened that the consumers preferred the decoy option itself which can be partially caused by the specific nature of the product and the decision-making itself. For the product category holiday destination consumers preferred the cheapest competitor alternative when the decoy was both present and absent even though decoy was supposed to reduce its popularity which did not happen. 
For the rest of the products tested the difference in the consumer's choices when the decoy was absent and present was clear. Especially in the decision problem involving gym season tickets a significant shift of preferences towards target option was confirmed and it can be suggested for the decoys to be efficiently used for this kind of intangible product mostly because this type of product is described by a limited number of traits (price $\mathrm{x}$ number of entries) that consumers can base their decision on. Therefore, this makes the use of decoys in this case quite convenient also in the marketing practice. It was confirmed that the decoy worked and caused the increase in the popularity of the target also for the washing machines. However, contrary to the season tickets the practical use of the decoys, in this case, might mean a more complex challenge.

At the same time, authors assume there is still space for further research especially in the area of decoys in the foodservice industry whether the decoys might find their use there too, despite the role of tastes on humans' preferences. Another possible area for more detailed research is whether the practical use of decoys for products containing more dimensions is truly possible or whether adding more product traits and a variety of alternatives lessens the effect.

\section{Acknowledgement}

This research was financially supported by the Student grant competition project SGS/7/2017: "Acceptance of technology from the perspective of marketing tools."

\section{References}

[1] ARIELY, D., 2008. Predictably Irrational: The Hidden Forces That Shape Our Decisions. 1st ed. New York: Harper Collins. ISBN 978-0-00-725653-2.

[2] BAČOVÁ, V., 2013. Preferéncie a efekt atraktivíty v rozhodovaní. In R. Masaryk, ed., Rozhodovanie a usudzovanie V. Sociálne vplyvy v rozhodovaní. Bratislava: Ústav experimentálnej psychológie, pp. 45-68. ISBN 978-80-88910-46-6.

[3] CHUANG, S. CH. and R. YEN, 2007. The impact of a product's country-of-origin on compromise and attraction effects. Marketing Letters, 18(4), 279-291. ISSN 0923-0645.

[4] DHAR, R. and I. SIMONSON, 2003. The Effect of Forced Choice on Choice. Journal of Marketing Research, 40(2), 146-160. ISSN 0022-2437.

[5] ĎURINÍK, M., 2013. Influencing a Warranty Choice with the Introduction of an Inferior Alternative into the Choice Set. In: Proceedings of 6th International Scientific Conference. Karviná Ph.D. Conference on Business and Economics. Karviná: SU - OPF, pp. 249-257. ISBN 978-80-7248-901-5.

[6] FREDERICK, S., L. LEE and E. BASKIN, 2014. The limits of attraction. Journal of Marketing Research, 51(4), 487-507. ISSN 0022-2437.

[7] GONZALEZ-PRIETO, D., J. M. SALLAN, P. SIMO and R. CARRION, 2013. Effects of the addition of simple and double decoys on the purchasing process of airline tickets. Journal of Air Transport Management, 29, 39-45. ISSN 0969-6997.

[8] HA, Y. - W., S. PARK and H. - K. AHN, 2009. The influence of categorical attributes on choice context effects. Journal of Consumer Research, 36(3), 463-477. ISSN 0093-5301.

[9] HEATH, T. B. and S. CHATTERJEE, 1995. Asymmetric Decoy Effects on LowerQuality versus Higher-Quality Brands: Meta-Analytic and Experimental Evidence. Journal of Consumer Research, 22(3), 268-284. ISSN 0093-5301. 
[10] HUBER, J., J. W. PAYNE and C. PUTO, 1982. Adding Asymmetrically Dominated Alternatives: Violations of Regularity and the Similarity Hypothesis. Journal of Consumer Research, 9(1), 90-98. ISSN 0093-5301.

[11] LEVAV, J., R. KIVETZ and C. CHO, 2010. Motivational Compatibility and Choice Conflict. Journal of Consumer Research, 37(3), 429-442. ISSN 0093-5301.

[12] LIN, CH. - H., Y. - CH. SUN, S. - CH. CHUANG and H. - J. SU, 2008. Time Pressure and the Compromise and Attraction Effects in Choice. In A. LEE and D. SOMAN, eds. Advances in Consumer Research Volume 35. Duluth, USA: Association for Consumer Research, pp. 348-352. ISSN 0098-9258.

[13] LUCE, R. D., 1977. The Choice Axiom after Twenty Years. Journal of Mathematical Psychology, 15(3), 215-233. ISSN 0022-2496.

[14] MAO, W. and H. OPPEWAL, 2012. The attraction effect is more pronounced for consumers who rely on intuitive reasoning. Marketing Letters, 23(1), 339-351. ISSN 0923-0645.

[15] MILBERG, S. J., M. SILVA, P. CELEDON and F. SINN, 2014. Synthesis of attraction effect research: Practical market implications? European Journal of Marketing, 48(7/8), 1413-1430. ISSN 0309-0566.

[16] PARK, J. Y. and S. S. JANG, 2018. The Impact of Sold-Out Information on Tourist Choice Decisions. Journal of Travel and Tourism Marketing, 35(5), 622-632. ISSN 1054-8408.

[17] ROODERKERK, R. P., H. J. VAN HEERDE and T. H. A. BIJMOLT, 2011. Incorporating context effects into a choice model. Journal of Marketing Research, 48(4), 767-780. ISSN 0022-2437.

[18] SHOEMAKER, S., 1994. A Proposal to Improve the Overall Price Value Perception of a Product Line. Journal of Restaurant and Foodservice Marketing, 1(1), 89-101. ISSN 1052-214X.

[19] TOMEK, I., V. STŘÍTESKÝ and R. TAHAL, 2013. Segmentation of Czech Consumers Based on Their Attitudes towards Money. Central European Business Review, 2(2), 1924. ISSN 1805-4862.

[20] WU, CH. and K. COSGUNER, 2020. Profiting from the Decoy Effect: A Case Study of an Online Diamond Retailer. Marketing Science, forthcoming. ISSN 0732-2399.

[21] YANG, S. S. and M. LYNN, 2014. More Evidence Challenging the Robustness and Usefulness of the Attraction Effect. Journal of Marketing Research, 51(4), 508-513. ISSN 0022-2437. 